\title{
Comparative recognition of left ventricular thrombi by echocardiography and cineangiography
}

\author{
TOSHIHIKO TAKAMOTO,^ DUCKSOO KIM, $\dagger$ PAUL M URIE, $\ddagger$ DIANA F GUTHANER, $\dagger$

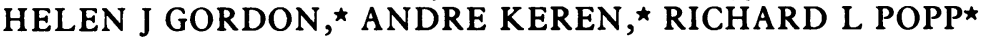 \\ From the ${ }^{\star}$ Cardiology Division, Department of Medicine, the + Department of Radiology, and the $\ddagger$ Department of \\ Pathology, Stanford University School of Medicine, Stanford, California, USA
}

SUMMARY Studies performed in 47 patients, 11 of whom underwent surgery for aneurysmectomy and 36 of whom underwent cardiac transplantation, were reviewed to assess the diagnostic accuracies of cross sectional echocardiography and cineangiography in detecting left ventricular mural thrombi and the effect of anticoagulation treatment on the incidence of such thrombi. Cross sectional echocardiography in 37 patients and cineangiography in 26 (16 patients were examined by both methods) were analysed independently by sets of two observers experienced in the respective methods. All four observers were blinded to the pathological or surgical findings regarding mural thrombus. Mural thrombus was confirmed by pathological investigation in 14 of $47(30 \%)$ cases; 11 of these 14 patients had intra-aneurysmal thrombi. The negative predictive value was quite good for both methods, but cross sectional echocardiography had a superior positive predictive value. This was due both to detailed soft tissue resolution by cross sectional echocardiography and to overdetection of mural thrombi by cineangiography in cases of aneurysms without mural thrombi. Mural thrombi were present in three of 20 patients with preceding anticoagulation and in 10 of 19 patients without anticoagulation. The results emphasise that cross sectional echocardiography is more reliable than cineangiography in recognising thrombi.

Recognition of left ventricular mural thrombi may be important before cardiac surgery or when anticoagulation treatment is considered. Recent experience has shown that cross sectional echocardiography is useful in detecting left ventricular thrombi. ${ }^{1-6}$ Left ventricular cineangiography has also been used to diagnose this problem. ${ }^{78}$ There have, however, been few systematic studies to examine the diagnostic accuracy of either cross sectional echocardiography or cineangiography in the detection of mural thrombi. ${ }^{9-13}$ In addition, controversy continues regarding the relative superiorities of echocardiography and angiography in the diagnosis of mural thrombi. This study is a retrospective analysis of the diagnostic accuracy of the two methods.

Requests for reprints to Professor Richard L Popp, Cardiology Division, Stanford University Medical Center, Stanford, California, 94305, USA.

Accepted for publication 3 August 1984

\section{Patients and methods}

Between January 1980 and March 1983, 107 patients underwent open heart surgery for aneurysmectomy or heart transplantation at Stanford University Medical Center. Fifty six of these patients underwent either cross sectional echocardiography or angiography or both at Stanford before surgery and were our initial study population. In this group five patients who had technically limited echocardiograms or angiograms were excluded, and another four were finally excluded because definite pathological confirmation regarding mural thrombi was not available. Finally, 47 patients (11 undergoing aneurysmectomy and 36 heart transplantation) were available for our study. They comprised six women and 41 men with a mean (SD) age of 41 (15) years.

\section{CROSS SECTIONAL ECHOCARDIOGRAPHY}

Cross sectional echocardiography was performed in 37 patients within five $(1.8(1.7))$ months before surgery with a Hewlett Packard model 77020A, Toshiba 
SSH-10A, or Irex System III ultrasound imaging system, using a $2.5 \mathrm{MHz}$ or $3.5 \mathrm{MHz}$ medium or short focused transducer. Echocardiograms were interpreted independently by two experienced observers who were blinded to the radiological, pathological, or surgical findings regarding thrombus. The cross sectional echocardiographic criteria for mural thrombi were: (a) one or more masses of echoes adjacent to the left ventricular wall but distinct from the endocardial echo; $(b)$ different visual texture of echoes from the adjacent myocardium; (c) asynergic motion of the adjacent ventricular myocardium; (d) occasional mobile projections from the mass into the ventricle; and $(e)$ location of the abnormal echoes, usually at the apex. After the initial blind reading had been done by each observer the final decision on the presence or absence of mural thrombi was made by consensus.

\section{LEFT VENTRICULAR CINEANGIOGRAPHY}

Left ventriculography was performed in the $30^{\circ}$ right anterior oblique projection at $60 \mathrm{frames} / \mathrm{s}$ with high resolution caesium iodide intensifiers (Siemens or General Electric). Cine recording of radio-opaque grids at the end of every case verified a minimum of two line pairs/mm resolution. Cineangiography was performed in 26 patients within five (1.6 (1.5)) months before the operation and was analysed independently by two experienced radiologists who also were blinded to the echocardiographic, pathological, or surgical information. A final decision was made by consensus. The diagnosis of mural thrombi by contrast ventriculography was based on $(a)$ a filling defect persisting throughout the cardiac cycle and (b) a smooth ventricular outline with apparent truncation or loss of normal left ventricular shape.

\section{PATHOLOGICAL AND SURGICAL CONFIRMATION}

The pathology reports reviewed for this project included the presence, absence, size, location, and general histological findings of the mural thrombi as well as reports of any associated ventricular aneurysm. In the event that necessary information was missing from a patient's initial pathological report on file, hearts from the transplant recipients were reexamined by the pathologist for the purpose of this study. Surgical findings of mural thrombi during aneurysmectomy were available in the patient's medical records in the operative reports.

\section{STATISTICAL ANALYSIS}

Sensitivity was calculated as true positive/(true positive + false negative) $\times 100(\%)$; specificity as true negative/(true negative + false positive) $\times 100(\%)$; positive predictive value as true positive/(true positive + false positive) $\times 100(\%)$; and negative predictive value as true negative/(true negative + false negative) $\times 100(\%)$. Fisher's exact probability test was used to compare the interobserver differences in the analysis of the presence or absence of mural thrombi by echocardiography and cineangiography. The incidence of mural thrombi in the group treated with anticoagulant agents and the untreated group was compared using $\chi^{2}$ analysis with Yates's correction. ${ }^{14}$ Significance was defined as a $\mathrm{p}$ value $<0.05$.

\section{Results}

Of the 47 patients studied, 24 had coronary artery disease, 19 primary idiopathic cardiomyopathy, two valvar heart disease, and two congenital heart disease. A left ventricular thrombus was confirmed in 14 of the $47(30 \%)$. The incidence of mural thrombi in coronary artery disease and in cardiomyopathy was $50 \%$ ( 12 out of 24 ) and $11 \%$ (two out of 19 ) respectively. Eleven of the 12 thrombi in the patients with coronary artery disease were within aneurysms. The sizes of the thrombi varied from $1.5 \mathrm{~cm}^{3}$ $(2.0 \times 1.5 \times 0.5 \mathrm{~cm})$ to $65 \mathrm{~cm}^{3}$ (radius $2.5 \mathrm{~cm}$, sphere). The thrombi noted in the two patients with cardiomyopathy were both remarkably large with partial adhesion to the left ventricular wall and extension well into the ventricle. Thirteen thrombi were located in the apex and one at the posterior wall; $11(79 \%)$ of the 14 thrombi were intra-aneurysmal. All the thrombi seen in the aneurysms were overlying the aneurysm bed and were firmly attached to the scarred myocardium or were identified under an endothelialised surface of the organised thrombus. The thrombi associated with myocardial aneurysms were all laminated and did not protrude into the ventricle.

There was observer disagreement regarding the interpretation of mural thrombi on echocardiograms in five cases (the consensus reached was two positive and three negative) and on cineangiograms in four cases (consensus reached was all four negative). The interobserver differences were not significant.

\section{CROSS SECTIONAL ECHOCARDIOGRAPHY}

Of the 37 patients evaluated by cross sectional echocardiography, 10 had true positive cases of mural thrombi, three false positive, 22 true negative, and two false negative. Thus sensitivity was $83 \%$, specificity $88 \%$, positive predictive value $77 \%$, and negative predictive value $92 \%$. In the true positive cases the actual sizes of mural thrombi, as determined by pathological investigation, were closely estimated by the measurements made with cross sectional echocardiography (Fig. 1). A large mural thrombus was, however, appreciably underestimated in size in one instance (Fig. 2). The smallest mural thrombus detected by cross sectional echocardiography was $2 \times 2 \times 1.5 \mathrm{~cm}$. Mural thrombi were clearly differenti- 

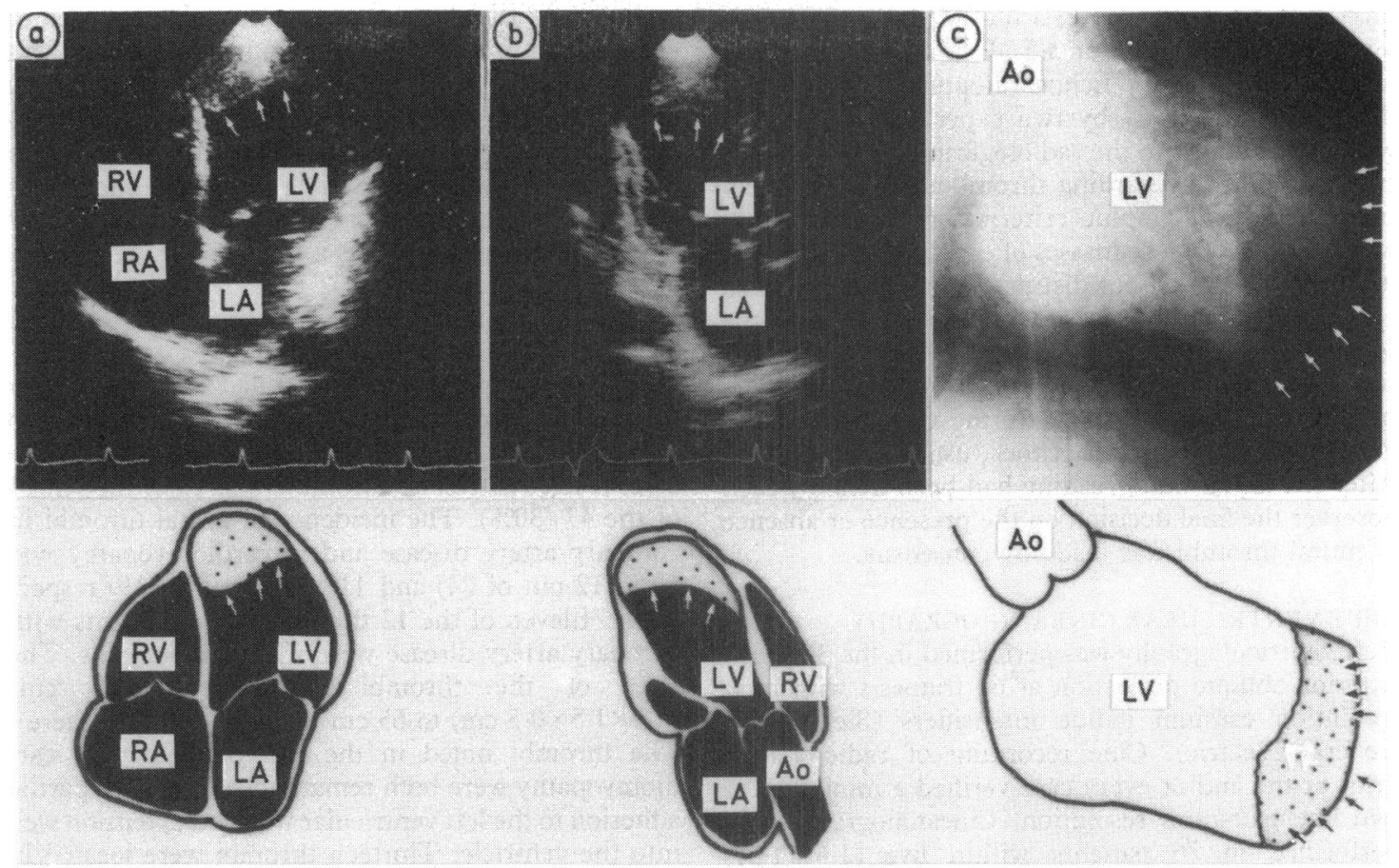

Fig. 1 Echocardiograms in the (a) apical four chamber view and (b) apical long axis view and (c) a right anterior oblique angiogram in a 65 year old man with extensive anterior myocardial infarction. Both cross sectional echocardiography and cineangiography were performed within a week before surgery. A mural thrombus at the apex is seen (arrows) in (a) and a sharp cut off of contrast distant from the apex (arrows) in (c). Ao, aorta; $L A$, left atrium; $L V$, left ventricle; $R A$, right atrium; $R V$, right ventricle. Schematic drawings are provided for illustration (lower panels).
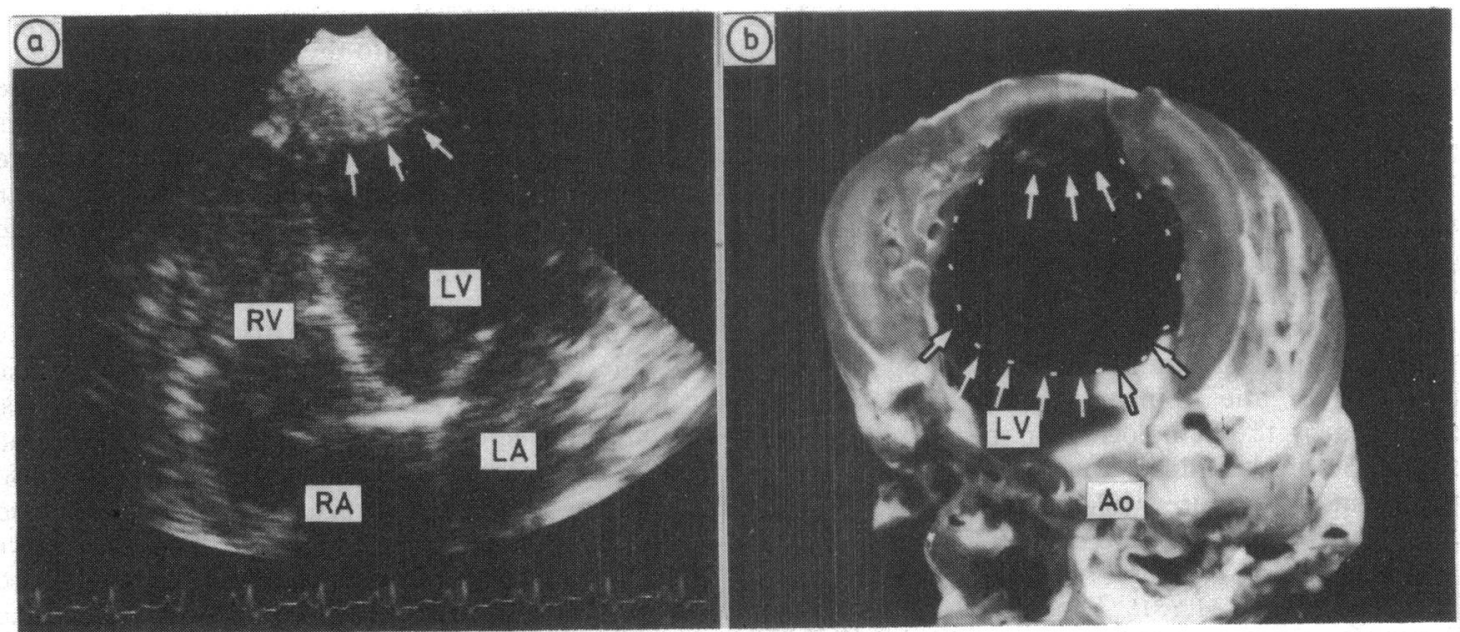

Fig. 2 (a) Echocardiogram and (b) pathology specimen from a 14 year old girl with cardiomyopathy. (a) The echo was read as positive in the apical four chamber view but the thrombus was appreciably underestimated in size (arrows). (b) A large spherical thrombus (dots and arrows), virtually filling the ventricle, was found at surgery for heart transplant performed three days after the echocardiographic study. The pathology specimen has been oriented to place the apex as in the echocardiogram. The planes of section are different, but the huge thrombus is spherical so this could not account for the disparity in size. $R V$, right ventricle; $L V$, left ventricle; RA, right atrium; LA, left atrium; Ao, aorta. 

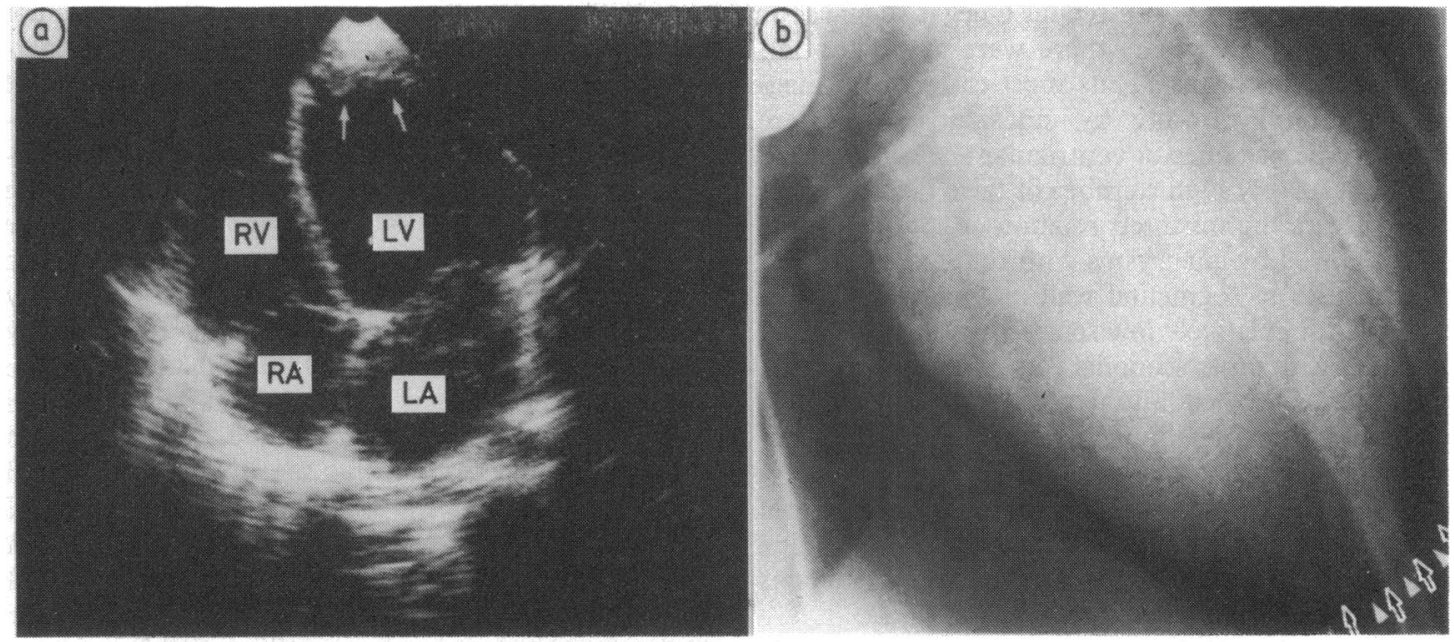

Fig. 3 (a) Echocardiogram in the apical four chamber view and (b) an angiogram from an 18 year old man with cardiomyopathy. (a) A mass of echoes at the apex was noted (arrows), but this corresponded to localised thick scar tissue without thrombus by pathology (false positive study by echocardiography). (b) No irregularity of the apex (arrows) was noted (true negative case). RA, right atrium; $L A$, left atrium; $R V$, right ventricle; $L V$, left ventricle.

ated from papillary muscles and muscle bands by their size, shape, and location. The pathological findings in the two patients with false negative thrombi both showed small thin thrombi attached to the apical endocardium, which were not visible on our echo studies. Endocardial fibrosis and localised thickened scar tissue without thrombi were found to be the basis of the false positive diagnoses (Fig. 3). Localised calcium in a mass of echoes at the ventricular apex was noted in one false positive case, in which the calcium was in pure scar tissue without associated thrombus.

\section{CINEANGIOGRAPHY}

Of the 26 patients who underwent cineangiography, five had true positive, six false positive, 12 true negative, and three false negative cases of mural thrombus. Thus sensitivity of the technique was $63 \%$, specificity $67 \%$, positive predictive value $45 \%$, and negative pre-
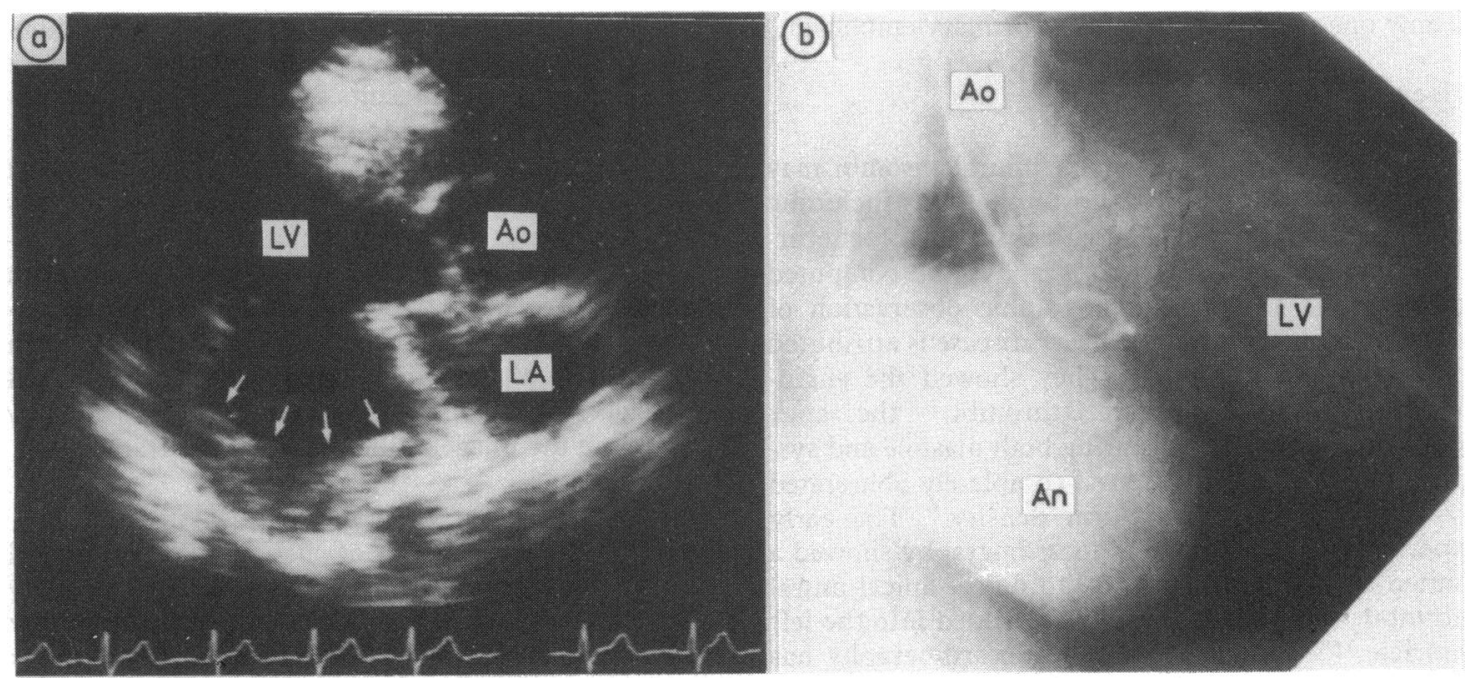

Fig. 4 (a) Echocardiogram in the parasternal long axis view and (b) an angiogram from a 45 year old man with inferior myocardial infarction. (a) A thick layered thombus (arrows) is shown in a posterior wall aneurysm. (b) The contour of the aneurysmal (An) sac is smooth and no filling defect is apparent. This was a false negative study by angiography. $L V$, left ventricle; LA, left atrium; Ao, aorta. 
dictive value $80 \%$. In all three false negative and four of six false positive cases there were associated left ventricular aneurysms. Thus most cases of misdiagnosis of mural thrombi by cineangiography were related to the presence of ventricular aneurysms (Fig. 4). The relatively high number of false positive cases resulted from the misinterpretation of contrast filling defects caused by aneurysms with rough surfaces and abnormalities of segmental wall motion. The factors related to the relatively low sensitivity of angiography compared with cross sectional echocardiography were obscuration of small mural thrombi or incomplete mixing of contrast medium within the apex. The factors related to the low positive predictive value were difficulties in distinguishing trabeculation from mural thrombi (one case), irregular ventricular contour due to prior aneurysmectomy (one case), and aneurysms with irregular walls (four cases).

\section{ANTICOAGULATION TREATMENT AND MURAL THROMBI}

Information regarding the presence or absence of anticoagulation treatment was available in 39 patients. Sodium warfarin, heparin, sulphinpyrazone, or dipyridamole were considered to be anticoagulants. Mural thrombi were present in three of 20 patients who had received at least four weeks' treatment with anticoagulants before heart surgery and in 10 of 19 patients who had not received anticoagulants $(p<0.05)$. Treatment with anticoagulants was begun after primary embolic events in four patients. None of these patients had subsequent emboli. Ventricular thrombus was sought and found by echocardiography in only one patient at the time of primary embolism.

\section{Discussion}

The presence of left ventricular mural thrombi may be assessed by several diagnostic methods including angiography, $M$ mode and cross sectional echocardiography, radionuclide scintigraphy, and computed tomography. The first angiographic observation of mural thrombi in coronary artery disease is attributed to Hamby et al in 1974. ${ }^{7}$ They showed the angiographic features of mural thrombi: "the apex appeared sharply cut off during both diastole and systole," and "the apex appeared completely obliterated by an irregular, non-uniform density." The early experience with $\mathbf{M}$ mode echocardiography showed a limited ability of this method to detect apical mural thrombi except when thrombi protruded into the left ventricle. ${ }^{15-17}$ Cross sectional echocardiography has proved to have an advantage in recognising mural thrombi that are predominantly at the ventricular apex. Previous studies, however, were done with early equipment, and uniform criteria for mural thrombi by either echocardiography or cineangiography were not established previously. ${ }^{1-31819}$ Our study was performed with generally accepted criteria on images of high quality from modern angiographic and echocardiographic instruments. Ezekowitz et $a l^{20}$ and Stratton $e a^{2}{ }^{21}$ reported their experience with radionuclide scintigraphy (platelets labelled with indium-111) for detecting left ventricular thrombi as highly specific (specificity 88-99\%) but with relatively low sensitivity $(60-77 \%)$. Computed tomography, as reported by Godwin $e t a l^{22}$ and Tomoda et al, ${ }^{23}$ had soft tissue resolution that allowed them to distinguish thrombi from the ventricular wall. Tomoda et al reported computed tomography with a sensitivity of $100 \%$ and a specificity of $91 \%$ for detecting left atrial thrombi but did not refer to left ventricular thrombi. ${ }^{23}$ Both this type of radionuclide scintigraphy and computed tomography are, however, expensive, and facilities for performing them are not generally available.

\section{LIMITATIONS OF CROSS SECTIONAL}

ECHOCARDIOGRAPHIC DIAGNOSIS

The diagnostic accuracy of cross sectional echocardiography for mural thrombi in our series (sensitivity $83 \%$, specificity $88 \%$ ) was in the range previously reported (sensitivity $72-95 \%$, specificity $86-90 \%$ ) by others. ${ }^{-11}$ The size and location of mural thrombi were well estimated by cross sectional echocardiography, except in one case of a large fresh homogeneous thrombus (Fig. 2). The discrepancy in this case between the echocardiographic and pathological findings was probably because of the low and uniform echogenicity of the fresh thrombus. ${ }^{24} 25$ The reasons for the misinterpretations of thrombi by echocardiography, compared with pathological findings, have been discussed in the results section and may be limitations that can be addressed by further improvements in diagnostic echocardiography. We found that the medium range focused transducers occasionally masked the near field with extraneous echoes at standard gain settings. We have recently used both medium $(6-8 \mathrm{~cm})$ and short $(2-5 \mathrm{~cm})$ focused transducers routinely when abnormal echoes have been suspected in the ventricular apex. A short focused transducer may help in difficult or equivocal cases by improving the image in the area near the transducer.

\section{LIMITATIONS OF ANGIOGRAPHIC DIAGNOSIS}

The diagnostic accuracy of angiography for mural thrombi in our series (sensitivity $63 \%$, specificity $67 \%$ ) was in the range of previous reports (sensitivity 31-73\%, specificity $75-92 \%$ ). ${ }^{12}{ }^{13}$ The relatively lower diagnostic accuracies of angiography compared with echocardiography may have been due to lower resolution, even with state of the art angiographic equipment, or inadequate criteria for distinguishing mural 
thrombi from the left ventricular wall. False negative studies may be explained by the absence of a filling defect in a laminated type of mural thrombus or contrast surrounding a small thrombus. Over detection of mural thrombi (false positive studies) may have occurred owing to an irregular contour of the left ventricular wall caused by trabeculae, muscle bands, or associated aneurysms without thrombi. ${ }^{26}$ Our study showed low positive predictive value (45\%) similar to the findings (57\%) of Reeder et al. ${ }^{12}$

\section{ANTICOAGULATION TREATMENT}

Since 1950 there have been arguments concerning the effectiveness of anticoagulation treatment for preventing the formation of mural thrombi and embolic phenomenon in high risk patients with coronary artery disease.$^{27}$ We found a significant difference $(p<0.05)$ in the incidence of thrombi between the patients who had received anticoagulation treatment for at least four weeks and those who had not. These results were similar to Keating et al's data ${ }^{28}$ but differed from those of Simpson et al ${ }^{29}$ and Swan et al. ${ }^{30}$ None of the five patients who had embolic events in our series had received previous anticoagulation treatment. Information regarding the dose, duration, interruption, or absence of anticoagulation treatment in patients without embolic events was not, however, uniformly obtainable throughout the follow up period, so a statistical comparison could not be made. Kallichurum et al reported a prevalence of emboli noted in lung, kidneys, spleen, myocardium, and brain as high as $58 \%$ in patients with cardiomyopathy at postmortem studies. ${ }^{31}$ Our study included only clinically manifest emboli.

As this study was performed retrospectively, it has some limitations: (a) the lack of uniformity of the examination technique in both cross sectional echocardiography and angiography; (b) the limited number of patients (16 out of 47 ) examined by both echocardiography and cineangiography; and $(c)$ the time between the examination date and date of operation. Attempts to standardise the examination technique in our laboratory have, however, been emphasised since 1979.32 Direct comparison of the two methods in the same patients would have been opti$\mathrm{mal}$, but the 16 patients examined by both techniques are of special interest in view of the false positive results by angiography: of the four angiographically false positive cases, two were correctly interpreted as negative and two were also falsely positive by echocardiography. Finally, chart and pathological report reviews did not lead us to believe that gross embolism of mural thrombus developed between echocardiographic or angiographic study and examination by pathology or surgery.
TT was supported by a research fellowship funded by the Ministry of Education in Japan. AK was supported by a Fogarty fellowship grant and the Israeli Heiden fellowship.

\section{References}

1 Ports TA, Cogan J, Schiller NB, Rapaport E. Echocardiography of left ventricular masses. Circulation 1978; 58: 528-36.

2 DeMaria AN, Bommer W, Neumann A, et al. Left ventricular thrombi identified by cross sectional echocardiography. Ann Intern Med 1979; 90: 14-8.

3 Meltzer RS, Guthaner D, Rakowski H, Popp RL, Martin RP. Diagnosis of left ventricular thrombi by twodimensional echocardiography. $B r$ Heart $\mathcal{f}$ 1979; 42: 261-5.

4 Asinger RW, Mikell FL, Sharma B, Hodges M. Observations on detecting left ventricular thrombus with twodimensional echocardiography: emphasis on avoidance of false positive diagnoses. Am $\mathcal{F}$ Cardiol 1981; 47: 145-56.

5 Meltzer RS, Roelandt J. Echocardiographic diagnosis of complications of myocardial infarction. In: Roelandt J, ed. The practice of $M$-mode and two-dimensional echocardiography. The Hague: Martinus Nijhoff, 1983: 276-80.

6 Weyman AE, Doty WD. Left ventricle. In: Weyman AE, ed. Cross-sectional echocardiography. Philadelphia: Lee and Febiger, 1982: 324-7.

7 Hamby RI, Wisoff BG, Davison ET, Hartstein ML. Coronary artery disease and left ventricular mural thrombi: clinical, hemodynamic and angiocardiographic aspects. Chest 1974; 66: 488-94.

8 Guthaner DF, Wexler L. Ventricular aneurysm. In: Teplick JG, Haskin ME, eds. Surgical radiology. Philadelphia: WB Saunders, 1981:1846-58.

9 Al-Nouli MB, Patel K, Johnson WD, Kamath ML, Schmidt DH. The sensitivity and specificity of twodimensional echocardiography in detecting left ventricular thrombi [Abstract]. Circulation 1980; 62 (suppl III): 21.

10 Reeder GS, Tajik AJ, Seward JB. Left ventricular mural thrombus: Two-dimensional echocardiographic diagnosis. Mayo Clin Proc 1981; 56: 82-6.

11 Stratton JR, Lighty GW Jr, Pearlman AS, Ritchie JL. Detection of left ventricular thrombus by twodimensional echocardiography: sensitivity, specificity, and causes of uncertainty. Circulation 1982; 66: 156-66.

12 Reeder GS, Lengyel M, Tajik AJ, Seward JB, Smith HC, Danielson G. Mural thrombus in left ventricular aneurysm: incidence, role of angiography, and relation between anticoagulation and embolization. Mayo Clin Proc 1981; 56: 77-81.

13 Lazar AV, Pechacek LW, Castro CM, Sonnemaker RE, Hall RJ. Comparison of two-dimensional echocardiography, radionuclide ventriculography and cineangiography in detection of surgically documented left ventricular thrombus [Abstract]. F Am Coll Cardiol 1983; 1: 703.

14 Brown BW Jr, Hollander M. Comparing two success probabilities. In: Brown BW Jr, Hollander M, eds. Statistics: a biomedical introduction. New York: John Wiley and Sons, 1977: 173-93. 
15 Hogan JH, O'M Shiel F, Goodman AC. Demonstration of left ventricular thrombus by conventional echocardiography. FCU 1976; 4: 287-8.

16 DeJoseph RL, Shiroff RA, Levenson LW, Martin CE, Zelis RF. Echocardiographic diagnosis of intraventricular clot. Chest 1977; 71: 417-9.

17 Kramer NE, Rathod R, Chawla KK, Patel R, Towne WD. Echocardiographic diagnosis of left ventricular mural thrombi occurring in cardiomyopathy. Am Heart $\mathcal{f}$ 1978; 96: 381-3.

18 van den Bos AA, Vletter WB, Hagemeijer F. Progressive development of a left ventricular thrombus: detection and evolution studied with echocardiographic techniques. Chest 1978; 74: 307-9.

19 Van Meurs-van Woezik HM, Meltzer RS, Van den Brand M, Essed CE, Michels RHM, Roelandt J. Superiority of echocardiography over angiocardiography in diagnosing a left ventricular thrombus. Chest 1981; 80: 321-3.

20 Ezekowitz MD, Burrow RD, Heath PW, Streitz T, Smith EO, Parker DE. Diagnostic accuracy of indium111 platelet scintigraphy in identifying left ventricular thrombi. Am f Cardiol 1983; 51: 1712-6.

21 Stratton JR, Ritchie JL, Hammermeister KE, Kennedy JW, Hamilton GW. Detection of left ventricular thrombi with radionuclide angiography. Am $\mathcal{f}$ Cardiol 1981; 48: 565-72.

22 Godwin JD, Herfkens RJ, Skiöldebrand CG, Brundage BH, Schiller NB, Lipton MJ. Detection of intraventricular thrombi by computed tomography. Radiology 1981; 138: 717-21.

23 Tomoda H, Hoshiai M, Furuya $\mathrm{H}$, et al. Evaluation of intracardiac thrombus with computed tomography. Am $\mathcal{F}$ Cardiol 1983; 51: 843-51.
24 Mikell FL, Asinger RW, Elsperger KJ, Anderson WR, Hodges M. Tissue acoustic properties of fresh left ventricular thrombi and visualization by two-dimensional echocardiography: experimental observations. Am $\mathcal{F}$ Cardiol 1982; 49: 1157-65.

25 Mikell FL, Asinger RW, Elsperger KJ, Anderson WR, Hodges M. Regional stasis of blood in the dysfunctional left ventricle: echocardiographic detection and differentiation from early thrombosis. Circulation 1982; 66: 755-63.

26 Raphael MJ, Steiner RE, Goodwin JF, Oakley CM. Cine angiography of left ventricular aneurysms. Clin Radiol 1972; 23: 129-39.

27 Doscher NM, Poindexter CA. Myocardial infarction without anticoagulant therapy: deaths, emboli and an analysis of factors influencing mortality. Am F Med 1950; 8: 623-33.

28 Keating EC, Gross SA, Schlamowitz RA, et al. Mura thrombi in myocardial infarctions: prospective evaluation by two-dimensional echocardiography. Am $\mathcal{F}$ Med 1983; 74: 989-95.

29 Simpson MT, Oberman A, Kouchoukos NT, Rogers WJ. Prevalence of mural thrombi and systemic embolization with left ventricular aneurysm: effect of anticoagulation therapy. Chest 1980; 77: 463-9.

30 Swan HJ, Magnusson RT, Buchbinder NA, Matloff JM, Gray RJ. Aneurysm of the cardiac ventricle. Its management by medical and surgical intervention. West $\mathcal{f}$ Med 1978; 129: 26-40.

31 Kallichurum S. The heart in cardiomyopathy: a postmortem study. S Afr Med F 1976; 50: 1585-91.

32 Popp RL, Fowles R, Coltart DJ, Martin RP. Cardiac anatomy viewed systematically with two-dimensional echocardiography. Chest 1979; 75: 579-85. 